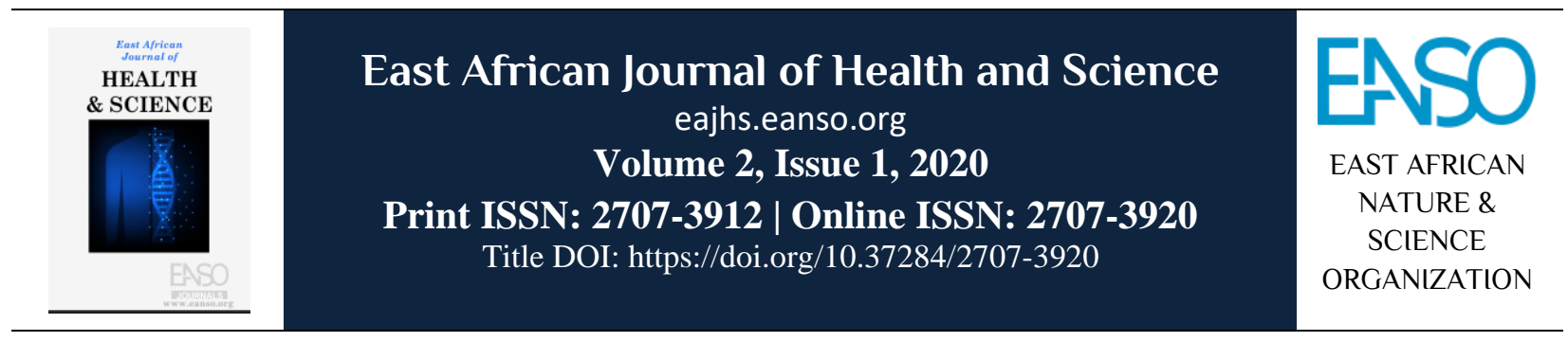

Original Article

\title{
Factors Associated with High Rate of Pregnancy Among Teenagers Aged 13- 19 Years in Nyatike Sub-County, Kenya
}

\author{
Kevin Otieno Oduor ${ }^{1^{*}} \&$ Beatrice Kithuka ${ }^{1}$ \\ ${ }^{1}$ The School of Public Health and Applied Human Sciences, Kenyatta University, Kenya. \\ *Author for correspondence email: oduorkevin@stowelink.com. \\ *ORCID: https://orcid.org/0000-0002-4680-3760
}

\section{Article DOI: https://doi.org/10.37284/eajhs.2.1.186}

\section{Date Published: ABSTRACT}

28 July 2020 One in every four girls in Nyatike Sub-county is expectant or has already begun childbearing. The girls in primary schools are getting pregnant at a higher rate

Keywords: than their counterparts in secondary schools. Due to the proximity to mining

Pregnancy Rates,

Teenagers,

13-19 Years,

Socio-Cultural Factor,

Socio-Demographic

Factors,

Nyatike Sub-County. sites and Lake Victoria, the cases of teenage pregnancies are constantly high. This study was carried out to determine the factors associated with a high rate of teenage pregnancy among teenagers aged 13-19 years in Nyatike Sub-county. Specifically, the study focused on determining the socio-demographic, socioeconomic, and socio-cultural factors associated with the high rate of teenage pregnancy in the sub-county. A cross-sectional descriptive study design was used. Self-administered questionnaires and in-depth interviews were used for data collection. A sample size of 311 respondents was used in the study. To arrive at the desired sample size above, a purposive/judgmental sampling technique was adopted. To analyze the data, the study adopted the use of Statistical Package for Social Sciences (SPSS version 20) and descriptive statistics. The study found out that poverty, lack of gainful employment, and inadequate sexual reproductive health services are enormously associated with early pregnancy among teenagers aged 13-19 years. The study also found out that proximity to the mining sites and lake are among the socio-demographic factors associated with teenage pregnancy. The study also determined that parents marry off their daughters at a tender age, religions permitting/embracing teenage pregnancy and lack of parental guidance are the socio-cultural practices associated with early teenage pregnancy. This study provides insights into the factors that are associated with teenage pregnancy and the disruptive approaches that can be adopted to address this public health concern. By the same token, 
this study fills the gap in previous studies in Nyatike Sub-county that have only concentrated on the prevalence of teenage pregnancy and not the factors associated with it.

\section{APA CITATION}

Oduor, K., \& Kithuka, B. (2020). Factors Associated with High Rate of Pregnancy Among Teenagers Aged 13-19 Years in Nyatike Sub-County, Kenya. East African Journal of Health and Science, 2(1), 38-50. https://doi.org/10.37284/eajhs.2.1.186.

\section{CHICAGO CITATION}

Oduor, Kevin, and Beatrice Kithuka. 2020. "Factors Associated with High Rate of Pregnancy Among Teenagers Aged 13-19 Years in Nyatike Sub-County, Kenya". East African Journal of Health and Science 2 (1), 38-50. https://doi.org/10.37284/eajhs.2.1.186.

\section{HARVARD CITATION}

Oduor, K. and Kithuka, B. (2020) "Factors Associated with High Rate of Pregnancy Among Teenagers Aged 13-19 Years in Nyatike Sub-County, Kenya", East African Journal of Health and Science, 2(1), pp. 38-50. doi: 10.37284/eajhs.2.1.186.

\section{IEEE CITATION}

K. Oduor and B. Kithuka, "Factors Associated with High Rate of Pregnancy Among Teenagers Aged 38-50 Years in Nyatike Sub-County, Kenya", EAJHS, vol. 2, no. 1, pp. 30-37, May 2020.

\section{MLA CITATION}

Oduor, Kevin, and Beatrice Kithuka. "Factors Associated with High Rate of Pregnancy Among Teenagers Aged 13-19 Years in Nyatike Sub-County, Kenya". East African Journal of Health and Science, Vol. 2, no. 1, May 2020, pp. 38-50, doi:10.37284/eajhs.2.1.186.

\section{INTRODUCTION}

Teenage pregnancy is considered to be the pregnancy that occurs before a lady celebrates her $20^{\text {th }}$ birthday; between 13-19 years of age (Odongo \& Ojwang, 2013). The definition is legally and morally acceptable even without regard to the marital status of the woman. Teenage pregnancy continues to be a huge public health concern with statistics revealing a shocking increase. Records from hospitals, primary schools, high schools, and higher learning institutions have greatly contributed to the statistics even as many teenagers conceive at an alarming rate. According to the report published by United Nations Population Fund (UNPF), about 378,300 adolescent girls in Kenya between the age of 10 and 19 years conceived between July 2016 and June 2017 (Boss, 2018). The report continues to reveal that out of this figure, 349,465 girls were teenagers between the age of 15 to 19years. Kenyan Health Demographic Survey revealed that one in every five girls between 15-19 years has begun childbearing or is already expectant (Amo-Adjei \& Anamaale, 2016).

Nyatike sub-county is not left out in these figures and it is hinted to contribute to the figures as well.
Nyatike sub-county has gold mines and Lake Victoria attributed to contributing to the cases of early pregnancies (Otengah \& Tabitha, 2018). A report by the Networks for Adolescent Youth in Africa (NAYA) shows that teenage pregnancy in the county stands at $24.3 \%$ after Narok, Homabay, and Nyamira (Juma, 2016). During the county dialogue forum organized by KELIN, a not for profit human rights organization working to promote and safeguard health-related human rights in Kenya, it was highlighted that cases of teenage pregnancies were rampant in the Nyatike subcounty. Further isolated news in Migori noted that a class six girl in Kimai Primary school committed suicide which continues to unearth the menace having a devastating implication on the lives of teenagers whilst challenging the quest for realizing the sustainable development agenda number 3; Good health and well-being (Juma, 2016). With these sobering statistics, it is only making sense that factors associated with teenage pregnancy in Nyatike be established.

As teenage pregnancy continues to be on the rise, the devastating impacts and the far-reaching ramifications have been so much pronounced that everyone is essentially perturbed. The government, policymakers, health workers, and ordinary citizens 
are feeling the pinch. The statistics and the figures reported by different organizations only serve to vindicate the premise that teenage pregnancy is a major concern in public health. Around 13,000 teenage girls are dropping out of school each year due to early pregnancy (Amo-Adjei \& Anamaale, 2016). This is a nationwide figure that is greatly contributed to by Migori County. The county ranks fourth out of 47 with a prevalence percentage of $24.3 \%$ behind Narok, Bombay, and Nyamira (Juma, 2016).

While all these happenings unfold, a little or no action is done to impede and bring down the early pregnancies. Many parents do not know how to approach the issues surrounding sex and sexuality. In fact, in other places, sex is considering a topic for the elderly, and teenagers should keep off the topic for sure. There is no concrete data on the causal factors for the elevated teenage pregnancy and even if they exist, they are discrete, have parallel funding, and not so consolidated. The data for Nyatike Sub-county alone is almost nonexisting, save for organizations such as KELIN and few others which have endeavoured to constantly hold dialogue to document and profile Sub-county as per teenage pregnancy prevalence. Therefore, this aimed to establish factors associated with a high rate of pregnancy among teenagers aged 13 to 19 years in Nyatike Sub-county. The objectives included to establish the socio-demographic factors associate with a high rate of teenage pregnancy; to examine the socio-economic factors associated with high rate teenage pregnancy; to establish the socio-cultural practices that are associated with the high rate of teenage pregnancy in Nyatike SubCounty.

\section{LITERATURE REVIEW}

\section{Teenage Pregnancy in Sub-Saharan Africa}

Teenage pregnancy in the African continent has been persistently rising with the figures contributed by several countries in the region (Abalos et al., 2014). World Health Organization conducts an annual survey to profile the extent of teenage pregnancies which has slowly but surely become a concern to the public health fraternity. Sub Saharan countries have their individual rates of early teenage pregnancy which cumulatively constitute the annual report produced by the WHO (Salami \& Ayegboyin, 2015).

According to $\mathrm{WHO}$, the African continent is conspicuously leading the world in teenage pregnancy with a prevalence of about $30 \%$. As per the report in 2017, Niger topped the list having 203.604 births per 100,000 women in the teenage bracket (Salami \& Ayegboyin, 2015). Similarly, Mali followed Niger closely with a figure of 174 . 44 and Angola at 166. 602. Mozambique, Guinea, and Chad recorded 142.5334, 141.6722, and 137.173 deliveries per 100,000 women in the teenage respectively. In general, women in the African continent get married at a much earlier age compared to the women elsewhere leading to teenage pregnancies (Taffa \& Mathew, 2003). 143 teenage pregnancies per 1,000 teenagers age 14-19 years are recorded in Africa (World Bank, 2015). The data from World Bank, as of 2015 records that Niger, Angola, Guinea, Mali, and Mozambique had the highest incidence of births among 14-19 years teenagers. In Nigeria, women age 20-24 were in marriage before 15 years of age and about $86 \%$ married before $18^{\text {th }}$ birthday; $54 \%$ of those surveyed had given birth in their teenage (Akpor \& Thupayagale-Tshweneagae, 2019).

The World Health Organization has reported in the previous annual reports, that the elevated teenage pregnancy with the adverse health and social consequences are pressing problems bedeviling both the low and middle-income earners Ganchimeg et al., 2014). Teenage girls are likely to develop severe complications during delivery and there is a greater likelihood that the babies born to them are premature or die shortly after birth (Okereke, 2010). More than often, the teenagers' developmental problems from the stigma, domestic battering in their quest to meet the demands of pregnancy and the health care needs of the baby. By the same token, the teenagers are likely to give up on school and contemplate marriage as the only next option (Abalos et al., 2014).

In the reports by the Health Demographic Survey (2014) in Nigeria, the factors associated with adolescent pregnancy were early marriages where the teenager would be forced or willfully give in to marriage before the $19^{\text {th }}$ birthday (Akpor \& Thupayagale-Tshweneagae, 2019). The poor social 
and economic support is also blamed for the incidences of pregnancy as some teenagers would give in to sexual advances in exchange for the basic needs. Curiosity and peer pressure immensely contributed to the high teenage pregnancy even as may young girls, in the event of making the sexual debut to have a taste of it, got pregnant in the process (Akpor \& Thupayagale-Tshweneagae, 2019).

\section{Teenage Pregnancy in Kenyan Schools}

Teenage pregnancy in the Kenyan Schools continues to escalate. This trend caught the attention of the Ministry of Education and the Teachers Service Commission with sheer panic. If the latest statistics by the TSC are anything to go by, then teenage pregnancy has become an issue that demands a lot of attention. A review by the Daily Nation Magazine indicated that 1,228 teachers have been sacked in the last seven years for having sex with minors, a situation that led to a sharp increase in the rate of teenage the report went further to establish that 151 paedophile teachers were pregnancy. What is more, dismissed in a short period between 2018 and this year alone presents a worrying scenario (Wanzala, 2020).

Just in the report alone, TSC chief executive Nancy Macharia tabled a report on teenage pregnancy in the parliament, before the education committee chaired by Bomet Senator Christopher Langat revealing that Kakamega County has the highest number of culprits, at 88. Similarly, the report from schools in Kisii, Homabay, Kitui, and Bungoma stood at 61, 60, 53, and 47 respectively. These figures represent the number of teachers that have been interdicted in the court of law for engaging in sexual advancement with minors (Wanzala, 2020).

While presenting these shocking statistics, Ms. Macharia was, however, quick to mention that teachers were only accountable for only $2 \%$ of all the pregnancies in school, maintaining that the communities were more obsessed with preying on school-going girls. At the same time, she mentioned that minors are vulnerable targets owing to their young age. As such, the adults take advantage of them, predisposing them to sexual advancement (Wanzala, 2020). It is not over yet, not over until the report by the Education Ministry that exposed the details on the rate of pregnancy is reviewed. Teenage pregnancies in Kenyan schools had hit an all-time-high with Narok County leading with $60 \%$ of the cases reported countrywide. In the same year (2018) at least 10 girls gave birth while having their $\mathrm{KCPE}$ as several others doing the last paper in form four (Wanzala, 2020).

\section{Teenage Pregnancy in Kilifi County}

Kilifi County lies in the coastal region of Kenya having been formed as a merger of Malindi and Kilifi Districts. The county has a population of about 1 million with the youth forming a larger proportion of the population. The county covers an expansive area of $12,245.94 \mathrm{~km}^{2}$. The main socioeconomic activity is tourism and hotelier services (CRA, 2013).

The county has reported the highest rate of teenage pregnancy coupled with child abuse and molestation. Ongala (2017) while repotting for the Standard Media Group indicates that the county has recorded 77 teenage pregnancy, 40 child marriages, and 153 cases of child defilement. According to the study conducted by the Kenya Demographic Health Survey, 29\% of the teenagers are expectant or have begun childbearing (Obare, Odwe \& Birungi, 2016). The report further indicated that 1 in every 5 girls in Kilifi county has begun childbearing (Waudo, 2017; Faith to Action Network, 2017).

The county has seen the consequences of teenage pregnancy with lower transition rates from primary to secondary and secondary to institutions of higher learning. The dropout rates have shot high with 13,000 teens getting pregnant every year (Waudo, 2017; Faith to Action Network, 2017). The pregnancy cases have led to lower educational attainment as many girls affected drop out of school only to end up starting married life. The county government embarked on various interventions to reduce teenage pregnancy. The youths were sensitized on issues around sexual and reproductive health aimed at reducing the prevalence.

\section{Teenage Pregnancy in Narok County}

Narok is situated on an area of $17,933 \mathrm{~km}^{2}$ with a population of about 900,000 according to Kenya County Fact Sheet. The county is found in the former vast Rift Valley province and mainly 
depend on wheat as the main cash crop. The main ethnic extraction is the Kalenjin community with other communities penetrating the border around the 1990s (CRA, 2013).

Narok County has had an all-time high teenage pregnancy standing at $70 \%$ surpassing the national average of $18 \%$ (AFP, 2018). The figure was quoted to be the highest as many girls have dropped out of school and begun to siring children. Dr. Patrick-the head of reproductive and maternal health blamed the increase of teenage pregnancy on the ignorance of sexual and reproductive health. Many teens have not had the necessary knowledge that would help them avoid risky sexual behaviours. This wasn't the only blame. The parents were also blamed for failing to establish a strong and coherent family, giving direction to the girls and the opposite sex on issues about sexuality (AFP, 2018).

\section{Teenage Pregnancy in Nyatike Sub-county}

Nyatike Sub-county lie is in the periphery of the county that is grappling with the case of high teenage pregnancy. Being in Migori County, the same trend that has been documented in the Subcounty. It is recorded that 1 in every 4 girls is either pregnant or is already in childbearing (Juma, 2016). A similar report that was produced by indicates that the pregnancy rate in Nyatike Sub-county has hit $24.3 \%$. This translates to almost the same figure that was provided by NAYA (Juma, 2016).

The cases of teenage pregnancy have been linked to many consequences. Once a lady becomes pregnant; because of the social stigma attached to early pregnancy, they cannot withstand the scolding they receive from their peers. That notwithstanding, teenage pregnancy in this region has led to low educational attainment. A report done by NCPD (2017) indicated that the Sub-county has a very low high school transition rate which stands at $20 \%$. This is a revelation of the consequences that have been advanced by a high teenage pregnancy rate. NCPD (2018) reported that the teenagers who were interviewed confessed that they couldn't withstand the stigmatization that comes along by conceiving while in school. And due to this, they contemplated marriage as the only solution since they could not go back to school where they are scolded by their peers.
Mining and Fishing are the main economic activities in Nyatike Sub-county and many vices are linked to these activities (Otengah \& Tabitha, 2018). Teenage pregnancy is very rampant around the beaches in the Sub-county as many young girls exchange sex for money. As per the report done by NAYA (2017), it was revealed that $60 \%$ of the girls who were interviewed confessed that poverty always pushes them to engage in sexual activities with the fishermen who payback with good money (Otengah \& Tabitha, 2018). Since they cannot afford the essentials like sanitary pads and underpants, the girls rely on the fishermen to provide for them those needs in exchange for unprotected sex.

The area around Osiri and Macalder in Nyatike Sub-county is endowed with small scale mining which is the major source of livelihood for the people living around and some coming from the neighbouring sub-counties (NCPD, 2017). The mining site has been attracting many people who are settling to do trade and other small businesses. But even as the site is growing, NAYS reported that there is an increase in sexual activity among the girls and the minors. Citing poverty, the girls revealed that they need to foot their bills hence retorted to such risky behaviour of unprotected sexual intercourse. The report further indicated that 70 percent of the girls around the Osiri mining site are either pregnant or have already delivered (NCPD, 2015). Nyatike Sub-county has remained in the corridors of underdevelopment orchestrated by several factors. The teenage pregnancy has been a menace that has dogged the area for quite a long time denying it the economic prosperity it deserves. There has been a very low transition rate to institutions of higher learning since many girls have had children before they could finish their schooling.

The process of designing an intervention requires an effective partnership and funds to mobilize people, purchase the logistics, and the essential requirements (Mutisya, 2020). This report sought to bridge the gap that has been left by prior researches in Nyatike Sub-county. While most of the researches that have been conducted mainly focuses on determining the prevalence of teenage pregnancy in Nyatike Sub-county, this research went a notch higher to assess the factors associated 
with early teenage pregnancy. As such, it is a detailed document that shall be reviewed to initiate interventions to high teenage pregnancy.

\section{RESEARCH METHODOLOGY}

\section{Study Area}

The study area was Nyatike Sub-county which lies in the expansive region of Migori County. The area has a population of 144,625 with females being slightly higher than that of males according to the 2019 census (KNBS, 2009). The population density of the area is 333 people per square kilometre. The population is mainly comprised of the young. Nyatike Sub-county is endowed with Lake Victoria as a natural resource. The main economic activities taking place in Nyatike Sub-county are Fishing, small scale farming, mining, and trade (KNBS, 2012).

Demographically, Nyatike Sub-county is inhabited by the Luo ethnic community. However, the other ethnic groups are also represented in a small proportion. The Kikuyu, Luhya, and Swahili have infiltrated into the area being attracted by the rich gold mine in Osiri and the fishing activities taking place in the beaches around Lake Victoria. Similarly, the Abasuba community are also inhabiting the area around Sori bay. (KNBS, 2012).

The majority of the people living in Nyatike are Christians with the Roman Catholic and Anglican Churches of Kenya (ACK) being very dominant. However, few protestants can also be sported in the Sub-county (Kenya Census, 2009).

\section{Study Design}

The study used a cross-sectional study design to gain a snapshot of the factors associated with a high rate of pregnancy among teenagers. The study population was a teenager between the age of 13 to 19 years. To select the study participants, purposive/judgmental sampling was used. For the study to achieve the desired sample size, the study adopted Fisher et al., (1998) formulae of sample size determination. Ninety-five $(95 \%)$ confidence level was used to generalize the findings in the study. $n=\frac{z^{2}(p-q)}{d^{2}}$ where $\mathrm{n}$ refers to the sample size that is desired in a study; $\mathrm{Z}$ is the standard normal deviate which is usually set as 1.96. This corresponds to a $95 \%$ confidence interval; $\mathrm{p}=$ established the prevalence of teenage pregnancy which is at $24.3 \% . \mathrm{d}=$ degree of accuracy desired which is $5 \%$.

$$
\mathrm{n}=\frac{1.96^{2}(0.243 * 0.757)}{0.05^{2}}=283
$$

About $10 \%$ of the sample size was added to make up for the non-response, there 311 respondents were targeted.

Data was collected using closed-ended questionnaires. In-depth interviews were conducted to aid in collecting accurate data. The collection of data was for 2 months. This was enough time frame to cover the expansive Nyatike Sub-county. This was through interviews with respondents from the sample population. Questionnaires and interviews were adopted to collect the necessary data for this study.

The data collected was coded using Microsoft excel and analyzed using Statistical Packages for Social Sciences (SPSS version 20). A summary was done using descriptive statistics presented through graphs and tables.

\section{RESULTS AND DISCUSSIONS}

Questionnaires were used as a major tool for data collection. The questionnaire was distributed in Kituka Primary, Paw Ndege Primary, Akala Secondary, and Kimai Mixed Secondary schools. The table below shows the questionnaire return rate in relation to the 311 questionnaires that were administered. Out of the 311 questionnaires, 100 questionnaires were administered in Kituka Primary School; 75 were returned, translating to $87 \%$ return rate. In Pap Ndege Primary School, 80 questionnaires were issued, 71 were returned translating to $88.75 \%$ return rate. Similarly, 50 questionnaires were issued in Kimai Primary, 35 were returned, translating to a $70 \%$ return rate. Akala Mixed Secondary was issued with 81 questionnaires, 68 of them were returned, translating to $83.92 \%$ return rate. Cumulatively, the questionnaire return rate was at $83.92 \%$ as 261 
questionnaires were returned out of the 311 questionnaires. The slightly low questionnaire return rate was a result of concurrent activities that were taking place in the schools at the time of data collection. In Kimai and Akala Secondary schools, students were sent home for school fees hence the low questionnaire return rate.

\section{The Demographic Characteristics of Respondents}

The majority of the respondents were male at 136 $(52.1 \%)$ respondents while $125(48.9 \%)$ were female. The number was almost equal although the number of males outnumbered the female counterparts since the schools in which the data was collected are male-dominated. The majority of the respondents were between the age of 17-19 and 1517 represented by $40.2 \%$ (105) and 39.5\% (103) respectively. Only $53(20.3 \%)$ respondents were between the age of 13-15. Out of the 261 respondents, $70.1 \%$ (183) were Christians, $19.5 \%$ (51) were Muslims, $4.2 \%$ (11) were Rastafarians $6.2 \%$ (16) belonged to the others religions.

\section{Socio-Demographic Factor Associated with High Teenage Pregnancy}

The study determined that most teenage pregnancy occurs between the age of 13-14. When asked why most pregnancy is sustained at this age, $38.7 \%$ of the respondents mentioned that most teenagers at this age are curious about sex and they tend to experiment, and, in the event, they become pregnant (Table 1). Due to being inexperienced or having little or no proper sexual knowledge, teenage girls between the age of 13-14 always find themselves on the receiving end of unintended pregnancy. While at it, some other respondents mentioned that most teenage girls between the age of 13-14 become pregnant since they do not have proper knowledge of the use of the available contraceptives. While they may have heard about the use of condoms in preventing unwanted/unintended pregnancy, the teenage girls of this age do not know how to properly use them. Even those who retort to using them do not use them properly ending up securing pregnancy anyway.
The study determined that $36.4 \%$ of pregnancy are secured between the age of 15-16, some percentages slightly below those between the age of 13-14 (Table 1). The rest of the respondents (24.9\%) recorded that most teenage pregnancy is secured at the age of 17-19 as there is more sexual activity taking place around this age. The teenagers at this age are sexually active and this translates to conception.

Table 1: Age bracket prone to pregnancy

\begin{tabular}{lll}
\hline Age & Frequency & Percent \\
\hline $13-14$ & 101 & 38.7 \\
$15-16$ & 95 & 36.4 \\
$17-19$ & 65 & 24.9 \\
Total & $\mathbf{1 9 8}$ & $\mathbf{1 0 0 . 0}$ \\
\hline
\end{tabular}

Nyatike Sub-county is endowed with casual gold mining sites. Many residents of the area depend on the mining site as it is their source of livelihood. The mining site has attracted even other people from the neighbouring countries who have resolved to trade in gold. While doing the gold trade, the informal settlement has sprouted in the Osiri and Matanda areas of Nyatike Sub-County. During the study, locals were interviewed and they mentioned that because of the mining sites, many children have been causally birthed as the gold miners cohabit with teenage girls in exchange for money and gifts. In his own words, one of the interviewees said:

Many children have been born out of wedlock since the mining site was discovered and most of them are born to teenage girls. We have had put strict punishment against anyone found culpable of impregnating the teenage girls banishing them from the vicinity of the mining site.

In yet another interview, the interviewee mentioned that many teenage girls have dropped out of school to scamper for the rare resource. Those teenage girls who have not found education to be their portion resort to staying at the mining site to perform some casual jobs such as laundry to earn at least a mint. While at it, they enter into causal relationship and cohabitation and the result is pregnancy. 
Nyatike Sub-County has a fair share of Lake Victoria which is a natural resource that it prides itself off for. A lot of fishing activity takes place in the beaches around the Lake and this has been the source of livelihood of many residents for quite some time. The fishing activity in the Lake has attracted many people and the population at the beaches along Lake Victoria has remained at an alltime high. With the increase in the population, the has been a proportional increase in vices along with the vices. Apart from the vices such as theft, casual sexual activities have remained rampant. Many teenage boys and girls have dropped out of school to make life at the beach characterized by easy money and casual relationships. About $90 \%$ of incidental relationship bread at the beach has resulted in a pregnancy (Otengah \& Tabitha, 2018).

In an interview with one of the locals, he mentioned that some teenage girls would exchange sex for fish. He also mentions that this is a common practice that has been going on for long and it has encroached so much so that it has become business as usual. Promiscuity is high around the lake and many teenagers have been recruited into this activity. While at it, the teenagers have secured pregnancy.

\section{Socio-Economic Factors Associated with Teenage Pregnancy}

Out of the 261 respondents, $52.1 \%$ (136) respondents recorded that poverty majorly associated with the high teenage pregnancy in Nyatike Sub-County (Table 2). When asked why they opined that poverty is associated with high teenage pregnancy, the respondents mentioned that many teenage girls from relatively poor families tend to become pregnant as they engage in sexual activities in order to secure their basic needs such as sanitary pads. Other respondents mentioned have forced many parents to marry off their daughter in the bid to secure the bride price. There is considerably low teenage pregnancy among teenagers from well-off families as they can obtain their necessities without having to engage in sexual intercourse to secure them. Residents of Nyatike Sub-County are generally low-income earners. The low income has orchestrated the high poverty index that is experienced in this area.

Table 2: Factors associated with teenage pregnancy

\begin{tabular}{lll}
\hline & Frequency & Percent \\
\hline Poverty & 136 & 52.1 \\
Parents marrying off their daughters at a tender age & 35 & 13.4 \\
Religion permit/embrace teenage pregnancy & 19 & 7.3 \\
Peer Pressure & 40 & 15.3 \\
Lack of parental guidance & 12 & 4.6 \\
Inadequate sexual reproductive health services & 19 & 7.3 \\
Total & $\mathbf{2 6 1}$ & $\mathbf{1 0 0 . 0}$ \\
\hline
\end{tabular}

Nyatike Sub-County has not been a beneficiary of most health services. The area has remained marginalized and most health services have not been initiated in the area. $7.3 \%$ (19) of the respondents (Table 2) confessed that the Subcounty has been neglected and the inadequacy of sexual reproductive health services could be blamed for the high rate of teenage pregnancy experienced in the area. Other respondents who gave this response mentioned that contraceptives are scarce and they are not in the rich of many teenagers. They do not have access to the common contraceptives like the condoms and this is forcing them to engage in sex without protection.
Yet in other instances, the respondents mentioned that comprehensive sexual education has not been introduced or embraced in many schools in the subcounty. They could mention that only a few, countable schools have taken comprehensive sexual education seriously though they could not mention these schools. The respondents opine that adequate sexual reproductive health services such as the constant supply of contraceptives and comprehensive sexual education could help reduce the ever-high-rate teenage pregnancy in Nyatike Sub-County. 
During the study, two residents of Nyatike Subcounty were interviewed and their opinion was sort on whether unemployment could also be a catalyst for teenage pregnancy. They were both in agreement that unemployment has contributed significantly to the increased teenage pregnancy. The duo mentioned that teenage girls from families with gainful employment can supply their basic needs without the need for teenagers to engage in sexual activity. They compared two families: one with gainful employment and the other without any form of employment and concluded that families without any form of employment tend to marry off their daughters in order to secure bride price or relieve them the burden of having to take care of the teenager while supplying their basic needs.

While the questionnaire distributed did not directly ask whether unemployment is associated with teenage pregnancy, it was determined that many respondents in the study were from families without gainful or any form of employment. This is believed to be true even to the families that have had their teenage girls becoming pregnant when they engaged in sexual activity in order to secure some basic needs. But during an interview, one interviewee mentioned that even other teenage girls from families with some form of employment still contracted pregnancy. There is no steady supply of income from these employments hence cannot comfortably handle the family needs. The table below shows the respondents in relation to the employment status of their parents. Out of the 261 respondents, $67.8 \%$ (177) of the respondents come from families with no employment while only $32.2 \%$ (84) are from the families with some form of employment. The study did not determine, though, whether these are gainful employment or casual employment.

\section{Socio-Cultural Practices Associated with a high rate of teenage pregnancy}

Parents marrying their daughters at a tender age is a practice that has been harboured for quite a long time. Parents are still viewing their daughters as a source of wealth when they are married as they will be able to secure the bride price once they are married. There is a saying that has been massaged by the locals that siring daughter is akin to welcoming wealth. About $13.4 \%$ of respondents mentioned that many parents are marrying off their daughters even before they are of the right age to be considered for proposal in order to secure the bride price (Table 3). This cultural practice has continued to add the number of teenage pregnancies as these teenagers have conceived in their teen-age while in the marriage.

Table 3: Socio-Cultural practices associated with teenage pregnancy

\begin{tabular}{lll}
\hline Factors Associated with Teenage pregnancy & Frequency & Percent \\
\hline Poverty & 136 & 52.1 \\
Parents marrying off their daughters at a tender age & 35 & 13.4 \\
Religion permit/embrace teenage pregnancy & 19 & 7.3 \\
Peer Pressure & 40 & 15.3 \\
Lack of parental guidance & 12 & 4.6 \\
Inadequate sexual reproductive health services & 19 & 7.3 \\
Total & $\mathbf{2 6 1}$ & $\mathbf{1 0 0 . 0}$ \\
\hline
\end{tabular}

Regarding religion permitting/embracing teenage pregnancy, $7.3 \%$ of the respondents mentioned that religions permitting or embracing teenage pregnancy can be associated with the high teenage pregnancy in Nyatike Sub-county (Table 3). When asked why they held that opinion, the respondents mentioned that the places of worship have not played their role to instil morals among teenagers. In other circumstances, certain religions have not strongly come out to denounce pre-marital sex that is the cause of teenage pregnancy. It is even unfortunate that some religions consider that a child is a gift from the Lord and hence will embrace conception without reference to whether the pregnancy was procured within wedlock or without.

It is this laxity by the church, mosques, or other places of worship that $7.3 \%$ of the respondents faulted for the increase in teenage pregnancy. The 
religions themselves have not also embrace sexual education and sex is still a topic that is not discussed by elders together with the teenagers. It is still considered a taboo to talk about sex.

Concerning parental guidance on sexual and reproductive health; very few parents take their time to talk with their teenage sons and daughters on issues around sexuality. Parents have not surely grasped or even understood the need for them to create time and share with their children on sex. It is a topic that is considered to be mundane, vulgar, ungodly or opposed to heaven. This gap in upbringing has occasioned many teenagers to seek knowledge about sex by themselves, and in worst scenarios, experiment and have a taste of what sex is. In this, $4.6 \%$ mentioned that lack of proper parental guidance has contributed immensely to the increase in the rate of teenage pregnancy (Table 3).

In other instances, it is determined that religions are embracing childbearing even in teenagers. The research found out that while places of worship are regarded as institutions for morality, they had not come out so profoundly to denounce premarital sexual activities that result in teenage pregnancy. Some places of worship hold that a baby is a gift from God and that it doesn't necessarily matter at what age the so-called gift comes. A study was done by Ganchimeg et al., (2014) to determine the contribution of religion in instilling sexual morality. While the study determined that there is a great potential of the church in cementing morality, they were rather doing little or nothing at all to prevent premarital sexual encounter that would lead to early/teenage pregnancy.

Out of the 261 respondents, $15.3 \%$ mentioned that peer pressure is associated with teenage pregnancy since many teenagers, both boys and girls would want to follow what their peers are doing. In the haste to fit among their peers, the teenager would do everything that would make them identify with them including embracing vices such as premarital sex. Peer pressure may take different forms as in a relationship, sexual demands by a partner may be too much they end up engaging in unsafe sex as a way of expressing love. This manipulation leads to unprotected sex which leads to teenage pregnancy. In the interview, the study found that many schoolgoing teenagers tend to follow what their peers are doing, including engaging in sexual intercourse. Premeditated by the lack of a role model, a peer role model, the teenagers do not have someone they can look up to, to shape their moral while avoiding indulgence in premarital sexual activities that lead to teenage pregnancy.

\section{RECOMMENDATIONS}

There should be great education of the teenagers in the community on sexual health topics so that they become knowledgeable and responsible in the life choices they make. With the proper knowledge, teenagers will gain greater insight on how to plan their life and avoid horrible life experience such as having to carry a pregnancy in the teenage. The government, NGOs, faith-based organizations and other players should tap into these opportunity areas and close the gap on sexual education with the hope that this will help bring down the rate of teenage pregnancy.

Parental Guidance should be greatly promoted as it serves to help the teenager gain greater knowledge of sex and sexuality at home without having to seek this knowledge from outside while experimenting. The parents are at a vantage position to instil moral imprints among their children while encouraging them to shun premarital sexual activities that will derail their ambitions and goals in life. Promoting this culture will help reverse the negative trends in teenage pregnancy.

Establishing more youth groups and clubs has been tested and results show that it works. In line with the proverb that an idle mind is the devil's workshop, the actively engaged teenage population may not find the luxury of time to engage in immoral activities. The groups and the clubs act as a platform for inspiring the youth to push towards greatness without being derailed by immoral engagements.

Passage of stricter judgment/punishment against those found culpable of impregnating teenagers seems to create a punitive atmosphere, but if it can help to significantly reduce the rate of teenage pregnancy, so be it. If this is the only way sanity can be brought back into our societies, then this is a path that can be explored in order to reduce teenage pregnancy. Punishment has been meted on various 
individuals in other areas and the fear of being brought to book has helped reduced the number of teenage pregnancy cases.

\section{Figure 1: Recommendations by Respondents}

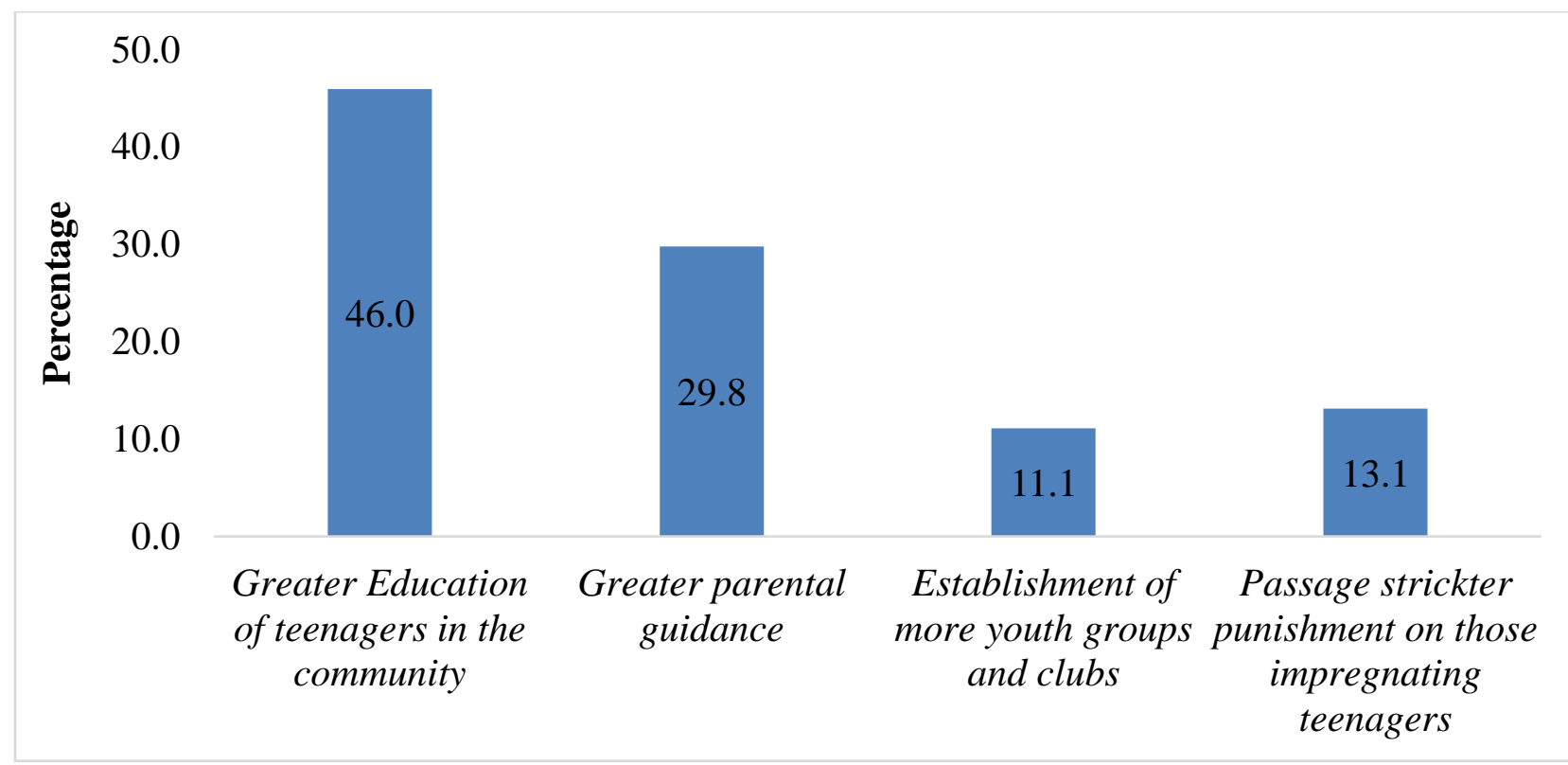

Research should be done to establish approaches that can be explored to significantly reduce the rate of teenage pregnancy in Nyatike Sub-County. With the research on approaches to reducing teenage pregnancy, the finding shall be very helpful in designing strategies that are impactful and result oriented.

\section{CONCLUSIONS}

Poverty is one of the major socio-economic factors associated with the high rate of pregnancy among the teenager. Due to the ravaging poverty, teenagers resort to sexual activities to meet their basic needs. Furthermore, many parents perceive their daughters as a source of wealth and they will stop at nothing to marry off their daughter to secure the bride price. These marriages are mainly negotiated at teenage hence contributing to teenage pregnancy. Lack of gainful employment or any form of employment is contributing to the increased rate of teenage pregnancy in Nyatike Sub-county. Peer pressure is dragging many teenagers into unprotected premarital sexual activities that lead to teenage pregnancy. The desire to identify with fellows make many teenagers indulge in activities that will make them achieve a sense of belonging. Some teenagers will also give in to unprotected sexual demands from partners as an expression of their true intimate feelings or love. The teenagers fallaciously believe that engaging in raw sex is a sign of true love; little do they know they run the risk of pregnancy and acquiring sexually transmitted infections.

Lack of parental guidance is eroding the morals of many teenagers as they go out to experiment or experience sex on their own. With their limited knowledge of sexual matters, they expose themselves to the ramifications that come along with it, including pregnancy. If the parents took their time to guide their children on sexual issues while they are still tender, the negative trends would be reversed. Religion can also help impart proper morals among teenagers and help cement guidance on sexual issues.

\section{REFERENCES}

Abalos, E., Cuesta, C., Carroli, G., Qureshi, Z., Widmer, M., Vogel, J. P., ... \& WHO Multicountry Survey on Maternal and Newborn Health Research Network. (2014). Pre-eclampsia, eclampsia and adverse maternal 
and perinatal outcomes: a secondary analysis of the World Health Organization Multicountry Survey on Maternal and Newborn Health. BJOG: An International Journal of Obstetrics \& Gynaecology, 121, 14-24.

AFP. (2018, Mar 16). Kenya's Narok County Reaches 3,000 Adolescents with Contraceptive Services Within 5 Months, Following Teenage Pregnancy Action Plan Approval. Retrieved from Advance Family Planning, at https://www.advancefamilyplanning.org/keny as-narok-county-reaches-3000-adolescentscontraceptive-services-within-5-monthsfollowing.

Akpor, O. A., \& Thupayagale-Tshweneagae, G. (2019). Teenage pregnancy in Nigeria: professional nurses and educators' perspectives. F1000Research, 8(31), 31 .

Amo-Adjei, J., \& Anamaale, T. D. (2016). Effects of planned, mistimed and unwanted pregnancies on the use of prenatal health services in sub-Saharan Africa: a multi-country analysis of demographic and health survey data. Tropical Medicine \& International Health, 21(12), 1552-1561.

Boss, K. (2018, Nov 26). Six shocking facts about teenage pregnancies in Kenya. Retrieved from Standard Digital https://www.standardmedia.co.ke/ureport/stor y/2001304092/six-shocking-facts-aboutteenage-pregnancies-in-kenya.

CRA. (2013). Kenya county fact sheets: June 2013. Kenya Commission of Revenue Allocation, available le at http://www.crakenya.org/wpcontent/uploads/2013/07/CRA-County-Factsheets-2nd-Edition-June-2013.pdf.

Faith to Action Network. (2017). Teenage Pregnancy in Kenya's Kilifi County: A qualitative study. Nairobi, Kenya: Faith to Action Network.

Fisher, L. D. (1998). Self-designing clinical trials. Statistics in medicine, 17(14), 15511562.
Ganchimeg, T., Ota, E., Morisaki, N., Laopaiboon, M., Lumbiganon, P., Zhang, J., ... \& Vogel, J. P. (2014). Pregnancy and childbirth outcomes among adolescent mothers: a World Health Organization multicountry study. BJOG: $A n$ International Journal of Obstetrics \& Gynaecology, 121, 40-48.

Juma, G. (2016, Jun 15). Migori County records $24.3 \%$ early pregnancy rate. Retrieved from Citizen Tv at https://citizentv.co.ke/news/migori-countyrecords-24-3-early-pregnancy-rate-130441/.

KNBS. (2009). Census in Kenya 2009. Nairobi, Kenya: Kenya National Bureau of Statistics.

KNBS. (2012). 2009 Kenya population and housing census: Counting our people for the implementation of Vision 2030. Nairobi: Kenya.

Mutisya, J. (2020, Mar 18). Kenya rates poorly in teen pregnancy war. Retrieved from Daily Nation News, available at https://www.nation.co.ke/newsplex/africanchil d/2718262-5158918-15u92tl/index.html.

NCPD. 2017. 2015 Kenya National Adolescents and Youth Survey (NAYS): Migori County. Nairobi, Kenya: National Council for Population and Development (NCPD). Available at https://ncpd.go.ke/wpcontent/uploads/2020/05/Migori-CountyAdolescents-and-Youth-Survey-NAYS.pdf.

Obare, F., Odwe, G. \& Birungi, H. (2016). Adolescent Sexual and Reproductive Health Situation in Kenya: Insights from the 2014 Kenya Demographic and Health Survey. STEP UP Research Programme Research Consortium. Nairobi: Population Council.

Odongo, F., \& Ojwang, S. B. (2013). Some aspects of teenage pregnancy in Nairobi: a prospective study on teenage mothers at Kenyatta National Hospital and Pumwani Maternity Hospital. East African Medical Journal, 67(6), 432-6.

Okereke, C. I. (2010). Assessing the prevalence and determinants of adolescents' unintended pregnancy and induced abortion in Owerri, 
Nigeria. Journal of biosocial science, 42(5), 619-632.

Ongala, M. (2017, Nov 12). Kilifi County has the highest number of teenage mothers and defilement cases. Retrieved from Standard Media Digital at https://www.standardmedia.co.ke/evewoman/a rticle/2001260002/child-abuse-kilifi-countyleads-with-153-defilement-cases.

Otengah, W., \& Tabitha, A. (2018). Parental Involvement in Teenage Pregnancy Prevention: A Study of Nyatike Sub-County, Migori County-Kenya. International Journal of Innovative Research and Advanced Studies, 5(9), 28-33.

Salami, K. K., \& Ayegboyin, M. (2015). Intergenerational Life Courses of Teenage Pregnancy in O Ogbomosho South-Western N Nigeria. Children \& Society, 29(5), 451-461.

Taffa, N., \& Matthews, Z. (2003). Teenage pregnancy experiences in rural Kenya. International journal of adolescent medicine and health, 15(4), 331-340.

Wanzala, O. (2020, Mar 18). Sex pests: 1,200 teachers sacked by TSC. Retrieved from Daily Nation https://www.nation.co.ke/news/Shame-ofteachers-who-prey-on-pupils/1056-502417812y $2 \mathrm{k} 7 \mathrm{az} / \mathrm{index} . \mathrm{html}$.

Waudo, D. (2017, Jan 16). Teen Mums of Kilifi. Retrieved from UNFPA Kenya available at https://kenya.unfpa.org/en/news/teen-mumskilifi.

World Bank. (2015). Adolescent Fertility Rate (Births per 1,000 Women Ages 15-19). Retrieved from World Bank, available at https://data.worldbank.org/indicator/SP.ADO. TFRT. 